\title{
CAPACIDADE DO SISTEMA DE LEVANTE HIDRÁULICO DOS TRATORES AGRÍCOLAS DE PNEUS NO BRASIL
}

\author{
André A. Veit $^{1 *}$, Airton dos S. Alonço ${ }^{l}$, Tiago R. Francetto ${ }^{l}$, Rafael S. Becker ${ }^{l}$, Mateus P. Bellé ${ }^{l}$ \\ ${ }^{1}$ Departamento de Engenharia Rural, Universidade Federal de Santa Maria, Santa Maria, Brasil.
}

*E-mail: andreh_veit@hotmail.com

Recebido em: $24 / 08 / 15$ Aceito em: 16/10/15

\section{RESUMO}

O sistema hidráulico do trator se torna importante por ser um modo de acoplamento de alguns implementos agrícolas, além de transmitir potência. Por isso, objetivou-se verificar as variações da potência do motor relacionadas com a capacidade de levante dos três pontos, a pressão máxima e a vazão máxima da bomba, além de se observar a capacidade de levante em função da massa do trator sem lastro. Para isso, foram coletados dados de 171 modelos de 11 marcas diferentes de tratores agrícolas de pneus. Estes foram classificados pela potência do motor segundo a ANFAVEA (Associação Nacional dos Fabricantes de Veículos Automotores) [1]. Foi construída uma planilha eletrônica para coletar as variáveis a serem estudadas. A vazão máxima da bomba foi a variável na qual menos foram encontrados dados, variando de 39,13 a 62,16\% nas diferentes Classes. Tratores da Classe II e III apresentaram as melhores relações quando uma das variáveis era a capacidade de levante. A variação média da vazão máxima da bomba relacionada à potência motora é proporcional, ou seja, tanto a vazão quanto a potência se elevaram igualmente, com valores médios de 0,79 até 1,09, nas diferentes Classes. A capacidade de levante apresenta incremento em função do acréscimo da massa total, da potência do motor e da vazão da bomba até equipamentos agrupados na Classe III; a partir desta, ocorre uma pequena redução das relações em função de o sistema de levante ser uma ferramenta secundária.

Palavras-chave: Sistema hidráulico de três pontos. Informação técnica. Seleção de máquinas agrícolas. Bomba do sistema hidráulico.

\section{Introdução}

Um segmento importante para atingir a atual produção de alimentos é a mecanização agrícola, pois surgiu como alternativa na melhoria das práticas de produção, possibilitando o aumentando da produtividade agrária [2]. O trator agrícola é a parte integrante dessa variável, que tem um papel crucial a desempenhar na ampliação dessa produtividade [3] pelo fato de que a principal fonte de potência do meio rural é o motor de combustão interna montado nessas máquinas, disponibilizandoas através da tomada de potência, da barra de tração e do sistema hidráulico [4].

Nesse sentido, a produção de tratores agrícolas de pneus vem crescendo consideravelmente nos últimos anos, alcançando 64.783 unidades produzidas em 2014, segundo os dados da Associação Nacional dos fabricantes de veículos automotores (ANFAVEA) publicados no Anuário da Indústria Automobilística Brasileira de 2015 [1].

Além disso, graças a sua versatilidade, eles são utilizados nas mais distintas atividades em conjunto com máquinas e implementos [5]. Todavia, o trator agrícola, além de versátil, deve ser robusto e possuir confiabilidade, apresentando segurança, conforto de trabalho e ter ampla capacidade de acoplamento nos diversos tipos de máquinas e implementos [6].

Dessa forma, torna-se necessária uma correta seleção dessas máquinas, uma vez que suas características e as suas respectivas relações influenciam de forma direta no seu desempenho. Consequentemente, os fatores que contribuem para o sucesso da atividade são a seleção e a utilização correta desses equipamentos, sendo que sua escolha adequada resulta do ajuste do planejamento da produção da propriedade, obtendo-se a máxima eficiência operacional e a capacidade efetiva de trabalho, reduzindo-se os custos.

Contudo, os usuários de tratores agrícolas se defrontam com uma série de decisões relacionadas no momento da seleção e a aquisição, visando a melhor eficiência de tais máquinas. Uma das formas de se realizar essa escolha é a busca de informações sobre o produto, pois, em uma atividade econômica, a disponibilidade de informações é essencial, já que esta deve possibilitar a comparação entre os modelos [7]. Apesar disso, os dados técnicos referentes às máquinas agrícolas são insuficientes e heterogêneos entre os fabricantes e modelos de uma mesma empresa tanto na forma quantitativa quanto qualitativa em virtude da não obrigatoriedade dos ensaios oficiais no Brasil, ficando a responsabilidade do fabricante pela apresentação [8]. Além disso, os tratores são

TECNO-LÓGICA, Santa Cruz do Sul, v. 20, n. 1, p. 55-61, jan./jun. 2016. 
providos de diversas características relevantes, de forma que sua avaliação conjunta é complexa e demorada. $\mathrm{O}$ agricultor tem dificuldade para escolher um modelo adequado em função das suas necessidades e das características específicas de sua propriedade, principalmente, pela heterogeneidade entre os catálogos e, em alguns casos, pela falta de informações claras e objetivas [9]. Do mesmo modo, a diversidade de máquinas disponibilizadas no mercado nacional torna a seleção ainda mais complexa.

Nesse sentido, para a melhor seleção de um trator agrícola, devem ser considerados diversos fatores para que a escolha seja mais próxima às necessidades do agricultor. Um quesito fundamental e o mais utilizado pelos agricultores é a potência do motor, que se define, resumidamente, na capacidade do motor em realizar trabalho em uma unidade de tempo. Além desta, têm-se inúmeros fatores, e dentre eles, pode ser destacado o consumo de combustível, a reserva de torque, bem como a capacidade de levante do sistema hidráulico. Esta última, que, muitas vezes, passa despercebida no momento da aquisição, pode ser fator fundamental em uma operação na qual se utilizam, necessariamente, equipamentos acoplados ao sistema de engate dos três pontos.

O sistema hidráulico é responsável por controlar a posição relativa dos implementos montados em relação ao solo, sendo tal operação realizada por um sistema mecânico de ligação, e a força exigida para abaixar ou levantar ocorre pela transmissão de uma força por meio do fluxo de óleo sob pressão. Além disso, o sistema hidráulico estabelece, entre o trator e o implemento ou uma máquina, um plano de acoplamento. Isso equivale dizer que entre ambas as partes não ocorrem movimentos relativos além daqueles controlados pelas articulações do sistema de acoplamento [7].

Dessa forma, por representar um dos componentes mais importantes dos tratores, objetivou-se analisar, avaliar e relacionar as características referentes à potência motora e à massa com os atributos do sistema hidráulico de levante de três pontos dos tratores agrícolas de pneus comercializados no Brasil, comparando-as de acordo com a classificação referente à potência motora, nas categorias I, II, III e IV.

\section{MATERIAL E MÉTODOS}

Foi realizada, primeiramente, a identificação das principais marcas fabricantes de tratores agrícolas de pneus no Brasil. Posteriormente, sucedeu-se ao levantamento das informações técnicas qualitativas e quantitativas desses equipamentos em suas versões padrões, obtidas em catálogos técnicos, manuais e folhetos disponibilizados pelas empresas e, quando necessário, pela busca direta com os fabricantes. Foi criado um banco de informações organizadas em uma planilha eletrônica, analisando-se e quantificando-se as variáveis separadamente, sendo elas: potência máxima do motor $(\mathrm{kW})$, capacidade de levante do sistema hidráulico (kgf), vazão máxima do sistema hidráulico $\left(1 \mathrm{~min}^{-1}\right)$, pressão máxima (kgf $\left.\mathrm{cm}^{-2}\right)$, controle, categoria e massa sem lastro $(\mathrm{kg})$. Além disso, determinaram-se as relações entre a capacidade de levante hidráulico em função da potência motora $\left(\mathrm{kgf} \mathrm{kW}^{-1}\right)$, da massa do trator $\left(\mathrm{kgf} \mathrm{kg}^{-1}\right)$ e da vazão máxima da bomba $\left(\mathrm{kgf} 1 \mathrm{~min}^{-1}\right)$. Também foram relacionadas a vazão máxima da bomba e a pressão máxima da bomba pela potência motora $\left(1 \min ^{-1} \mathrm{~kW}^{-1} \mathrm{e}\right.$

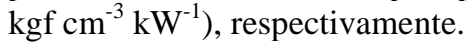

Todas as características foram estratificadas em função da potência motora, segundo a classificação adotada pela Associação Nacional dos Fabricantes de Veículos Automotores (ANFAVEA) [1]. De acordo com esta, tratores correspondentes à Classe $\mathrm{I}$ possuem potência de até $36,9 \mathrm{~kW}$; os da Classe II, de 37 a 73,9 kW; os da Classe III, de 74 a 146,9 kW; e os da Classe IV apresentam potência superior a $147 \mathrm{~kW}$.

As categorias que classificam o sistema hidráulico de tratores agrícolas procedem-se a partir da norma ISO 730-2009 [10]. Para fator de classificação, utiliza-se a potência na rotação nominal do motor dos tratores, obtendo-se, assim, as categorizações: I, com potência de até $48 \mathrm{~kW}$; II, de 30 a 92 $\mathrm{kW}$; III, de 60 a $185 \mathrm{~kW}$; e categoria IV, com potências de 110 a $350 \mathrm{~kW}$.

\section{RESULTADOS E DISCUSÃO}

Foram avaliadas as informações oriundas de 11 marcas, que englobaram um total de 171 modelos de tratores agrícolas de pneus. Foi verificado que 23 deles, correspondentes a $13,45 \%$, são dispostos na Classe I e 55, representando 32,16\%, estão na Classe II. A Classe III representou $32,74 \%$ do mercado, com 56 tratores, enquanto que a Classe IV apresentou 21,63\%, com 37 modelos. No entanto, foi identificado que as marcas não produzem tratores para todas as classes, sendo que 8 produzem modelos classificados como Classe I; todas fabricam tratores Classe II; 7 dispõem de modelos Classe III; e apenas 5 fabricam tratores classificados como Classe IV. Essa variabilidade ocorre porque cada fabricante objetiva atender um nicho específico de mercado.

$\mathrm{Na}$ Tabela 1, estão disponibilizados os valores máximos, mínimos e a média de potência motora, massa sem lastro, capacidade de levante, pressão máxima e vazão máxima da bomba nas diferentes Classes de potência.

Com o aumento das Classes de potência, observa-se que as médias da capacidade de levante se elevam proporcionalmente [11]. Porém, os valores máximos dessa característica na Classe I são maiores que a média da Classe II, fato que acontece devido à existência de um modelo de trator com baixa potência motora (Classe I) e elevada capacidade de elevação para manusear implementos integrados pesados. Esse mesmo caso ocorre nos valores de massa sem lastro, pressão máxima e vazão máxima da bomba.

TECNO-LÓGICA, Santa Cruz do Sul, v. 20, n. 1, p. 55-61, jan./jun. 2016. 
Na característica pressão máxima da bomba, nota-se que os valores máximos da Classe II são maiores que as médias da Classe III, bem como os máximos da Classe III com as médias da IV, fato explicado devido às características projetuais de cada fabricante.

Tabela 1. Valores máximos, médios e mínimos das características motora, ponderal e do sistema hidráulico.

\begin{tabular}{|c|c|c|c|c|c|}
\hline & $\begin{array}{l}\text { Potência máxima } \\
\text { motora }(\mathrm{kW})\end{array}$ & $\begin{array}{l}\text { Massa sem } \\
\text { lastro (kg) }\end{array}$ & $\begin{array}{l}\text { Capacidade de } \\
\text { levante (kgf) }\end{array}$ & $\begin{array}{l}\text { Pressão Máxima da } \\
\text { bomba }\left(\mathrm{kgf} \mathrm{cm}^{-2}\right)\end{array}$ & $\begin{array}{c}\text { Vazão Máxima da } \\
\text { bomba }\left(1 \mathrm{~min}^{-1}\right)\end{array}$ \\
\hline \multicolumn{6}{|l|}{ CLASSE I } \\
\hline Máximo & 36,80 & $3.135,00$ & $2.500,00$ & 214,00 & 43,00 \\
\hline Média & 28,06 & $1.822,21$ & 990,00 & 148,35 & 27,67 \\
\hline Mínimo & 10,80 & $1.065,00$ & 440,00 & 120,00 & 17,00 \\
\hline \multicolumn{6}{|l|}{ CLASSE II } \\
\hline Máximo & 71,50 & $5.702,00$ & $3.565,00$ & 214,00 & 80,00 \\
\hline Média & 53,47 & $3.050,12$ & $2.381,94$ & 195,27 & 42,92 \\
\hline Mínimo & 37,00 & $1.565,00$ & 850,00 & 180,00 & 17,00 \\
\hline \multicolumn{6}{|l|}{ CLASSE III } \\
\hline Máximo & 143,50 & $9.940,00$ & $8.400,00$ & 214,14 & 162,00 \\
\hline Média & 105,32 & $6.191,50$ & $5.294,48$ & 196,00 & 82,42 \\
\hline Mínimo & 69,87 & $3.630,00$ & $2.500,00$ & 180,00 & 35,00 \\
\hline \multicolumn{6}{|l|}{ CLASSE IV } \\
\hline Máximo & 492,00 & $19.979,00$ & $12.000,00$ & 219,23 & 428,00 \\
\hline Média & 268,28 & $12.257,91$ & $8.636,24$ & 205,63 & 229,07 \\
\hline Mínimo & 147,10 & $7.200,00$ & $6.780,00$ & 180,00 & 51,80 \\
\hline
\end{tabular}

Para que ocorra um acréscimo na capacidade de levante, considerando-se uma velocidade de elevação constante para todos os modelos, os projetos dos fabricantes visam aumentar o diâmetro do pistão, ocorrendo uma manutenção da pressão e um incremento da vazão máxima da bomba, visível pela pequena amplitude dos valores médios de pressão e um grande aumento na vazão da bomba com o aumento das Classes.

Na Tabela 2, pode-se visualizar o percentual de dados não disponibilizados pelos fabricantes referentes à massa, pressão máxima e potência máxima da bomba.

Tabela 2. Percentual de dados não disponíveis de massa, pressão máxima e vazão máxima da bomba.

\begin{tabular}{ccccc} 
& Classe I & Classe II & Classe III & Classe IV \\
Massa & 0,00 & 0,00 & 5,35 & 2,70 \\
$\begin{array}{c}\text { Pressão } \\
\text { máxima } \\
\text { Vazão }\end{array}$ & 26,08 & 10,90 & 14,28 & 0,00 \\
máxima & 39,13 & 45,45 & 44,64 & 62,16 \\
\hline
\end{tabular}

A vazão máxima da bomba foi a variável menos apresentada pelos fabricantes, variando de 39,13 a 62,16\% nas diferentes Classes, sendo a única que não é exibida em todas as
Classes. Dados de pressão máxima da bomba foram verificados na maioria dos catálogos, constatando-se que, para Classe IV, essa informação está presente em $100 \%$ dos modelos. Já na Classe I, tais dados foram encontrados em 73,92\% dos modelos e, na Classe II e III, 10,9\% e 14,28\% dos catálogos não continham esses dados, respectivamente. Já os dados sobre a massa das máquinas foram disponibilizados na maioria dos modelos, sendo que em apenas $5,35 \%$ e $2,70 \%$ dos equipamentos para a Classe III e IV, respectivamente, essa informação não constava.

A porcentagem de tratores com controle mecânico ou eletro-hidráulico, assim como a categoria do levante de três pontos, podem ser visualizados na Tabela 3. Essa Tabela descreve que tratores que possuem o sistema de controle mecânico de levante hidráulico são representados, na sua maior parte, pela Classe II, com 74,54\%, seguido de $47,82 \%$ na Classe I, 30,35\% na III e apenas 5,40\% dos tratores Classe IV apresentam esse sistema. Já o controle eletro-hidráulico é mais comum que o mecânico em tratores Classe III e IV, com $60,71 \%$ e $78,37 \%$ respectivamente, mas, nas Classes I e II, esse sistema é inexistente. Contudo, deve ser considerada a não disponibilização de dados sobre os tipos de sistemas que ocorreu em $52,17 \%$ na Classe I, $25,45 \%$ na II, $8,92 \%$ na III e $16,21 \%$ na IV.

TECNO-LÓGICA, Santa Cruz do Sul, v. 20, n. 1, p. 55-61, jan./jun. 2016. 
Tais informações corroboram com os resultados obtidos em pesquisas, que pela análise das informações técnicas de tratores agrícolas, verificaram a inexistência de um padrão entre as empresas e diferenças significativas nos catálogos de uma mesma marca, além da ausência de um grande número de informações, entre elas, as de acionamento do sistema de levante [8].

Tabela 3. Porcentagem de tratores referentes a controle de sistema hidráulico e categoria avaliada pela potência motora.

\begin{tabular}{ccccc}
\hline & Classe I & Classe II & Classe III & Classe IV \\
\hline CONTROLE & & & 30,35 & 5,40 \\
Mecânico & 47,82 & 74,54 & 60,71 & 78,37 \\
Eletrohidráulico & 0,00 & 0,00 & 8,92 & 16,21 \\
Sem dados & 52,17 & 25,45 & & 0,00 \\
\hline CATEGORIA & & & 0,00 & 0,00 \\
\hline Categoria I & 100,00 & 72,73 & 28,57 & 27,03 \\
Categoria II & 0,00 & 27,27 & 100,00 & 100,00 \\
Categoria III & 0,00 & 0,00 & 42,86 & \\
Categoria IV & 0,00 & 0,00 & &
\end{tabular}

Referente à categoria definida pela norma ISO 730-2009 [10], observa-se que todos os tratores Classe I se enquadram apenas na categoria I; na Classe II, 72,73\% deles estão na categoria I; e $27,27 \%$ na categoria II. Já na Classe III, os tratores analisados se enquadram nas categorias II, III e IV, com uma ampla diferença: 28,57, 100 e 42,86\%, respectivamente. Estes ultrapassam $100 \%$ porque as categorizações definidas pela norma podem enquadrar o mesmo trator, não exibindo percentagens absolutas. Esse fato também é visualizado na Classe IV, que apresenta $27,03 \%$ dos tratores na categoria III e $100 \%$ na IV.

A relação entre a capacidade de levante e a massa dos tratores conforme as suas Classes de potência está ilustrada na Figura 1.

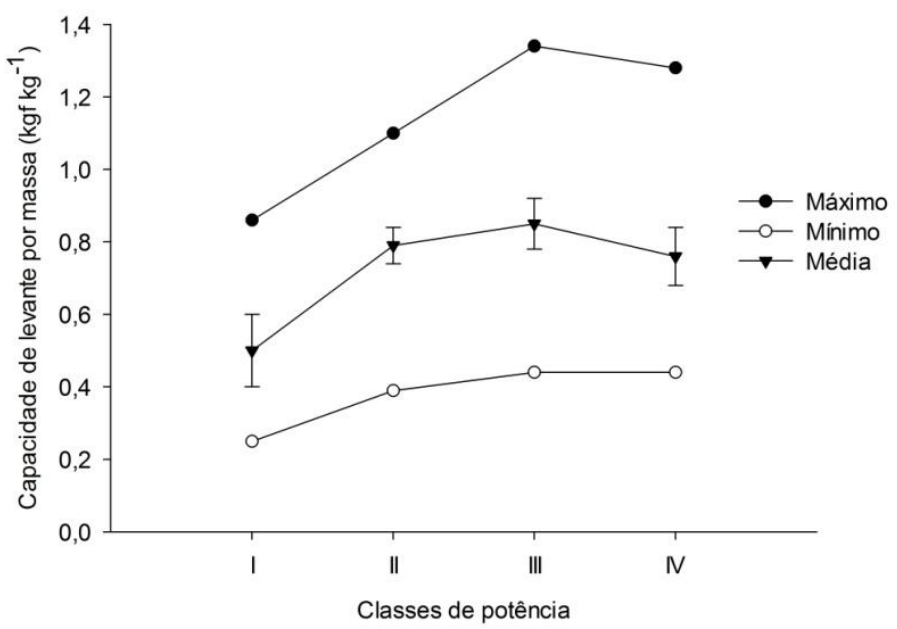

Figura 1. Relação entre capacidade de levante hidráulico pela massa do trator nas diferentes Classes
Com o aumento da potência, motora ocorre um aumento na relação capacidade de levante pela massa. Esse incremento é mais amplo da Classe I para a Classe II; é moderado da II para a III; e, para a II e III em relação à IV, essa associação diminui. Esse fato é explicado pelo aumento não linear da capacidade de levante com a massa nessa Classe, sendo que o valor da massa do trator aumenta e, em contrapartida, a capacidade de levante não aumenta proporcionalmente. Percebe-se uma grande elevação dessa relação média da Classe I para a II, elevando a média de 0,5 a $0,79 \mathrm{kgf} \mathrm{kg}^{-1}$. A baixa relação da Classe I pode ser explicada pelo fato de que esses tratores estão mais relacionados a serviços leves, nos quais a redução da massa provoca diminuição da resistência ao rolamento, aumentando sua versatilidade [12]. Para a Classe III, o valor médio da capacidade de levante foi de $5294 \mathrm{kgf}$ e na Classe IV de $8636 \mathrm{kgf}$. Entretanto, a massa da Classe III apresenta um valor de $6191 \mathrm{~kg}$, e a Classe IV, de $12.257 \mathrm{~kg}$, podendo ser observado que a massa aumentou praticamente o dobro da Classe III para a Classe IV, e a capacidade de levante foi apenas 1,6 vezes maior. Esse elevado aumento na Classe IV pode estar relacionado à melhor eficiência de tracionar implementos de arrasto, que é a principal função para essa Classe.

A diferença expressiva entre os valores mínimos e máximos em todas as Classes demostra que tratores da mesma Classe são dimensionados para realizar tarefas distintas, visto que cada projeto é considerado único na indústria, pois envolve, além de fatores estruturais e os direcionados ao desempenho, os critérios econômicos, necessitando sofrerem adaptações para a realização de determinados trabalhos. Esse fato é observado com maior ênfase na Classe II, III e IV, em que alguns tratores são dependentes de adição de lastros, objetivando obter a máxima capacidade de levante, pois a relação entre essas variáveis é

TECNO-LÓGICA, Santa Cruz do Sul, v. 20, n. 1, p. 55-61, jan./jun. 2016. 
maior que 1,0 quando analisado o valor máximo. Por consequência, a adição de lastro nesses tratores reduziria o valor dessa associação [3].

$\mathrm{Na}$ Figura 2, pode ser observada a relação entre a capacidade de levante do sistema hidráulico dos tratores e a potência motora nas diferentes Classes de potência.

Assim como apresenta a Figura 1, a relação da capacidade de levante pela potência motora dos tratores se eleva até a Classe III nos valores médios; na Classe IV, essa média cai bruscamente. Percebe-se isso, principalmente, pela grande elevação da potência dos tratores Classe IV, alcançando até 492 kW em comparação à Classe III, que possui potência máxima de $143 \mathrm{~kW}$, concluindo-se, assim, que a potência máxima da Classe IV é 3 vezes maior que a anterior. As maiores relações entre capacidade de levante e potência são verificadas nas Classes II e III, podendo ser explicado que essas máquinas têm grande necessidade do uso do sistema de três pontos em relação à Classe IV, que, como explicado anteriormente, seus principais implementos são acoplados pela barra de tração, que devido as suas dimensões e massas, são impossibilitados de serem acoplados ao engate de três pontos, o que justificam de certa forma, a variação nas capacidades encontradas.

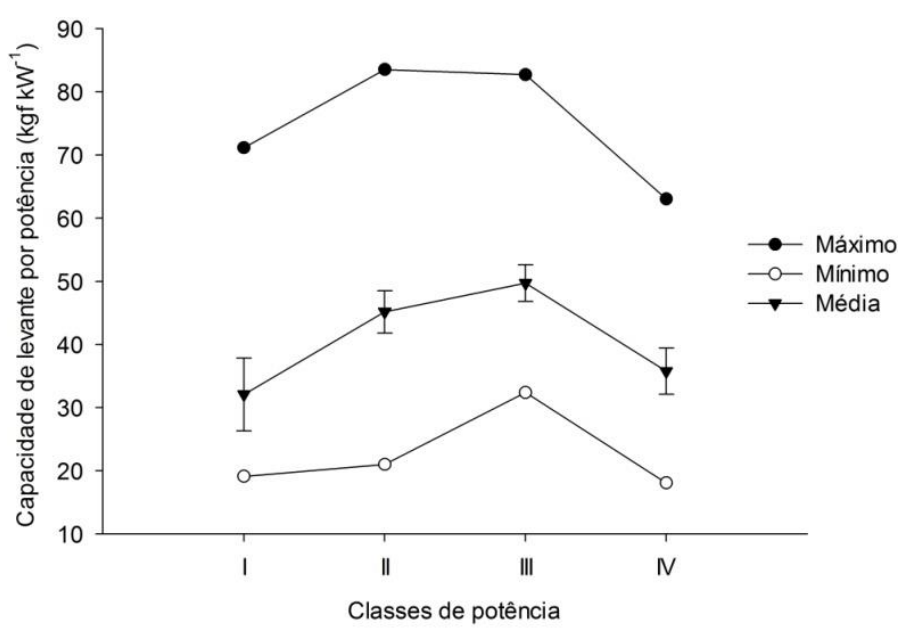

Figura 2. Relação entre capacidade do levante hidráulico pela potência nas diferentes Classes

A maior variação da relação foi constatada na Classe I, com 73,23\%, possivelmente, porque, nessa Classe, as empresas desenvolvem modelos que possam atender diferentes funções, que, em alguns casos, não precisam de levante hidráulico com grande capacidade, não necessitando de incrementos estruturais. A menor variação dessa relação foi obtida na Classe III, com $60,88 \%$, explicada em virtude de que as máquinas dessa Classe são fabricadas, geralmente, para o mesmo uso agrícola, na qual os implementos têm necessidades de capacidade parecidas.
Tratores de similar potência motora têm diferentes capacidades de levante, inclusive dentro de uma mesma marca. Em determinados casos, essa capacidade é demasiadamente superior à massa de implementos compatíveis com a potência, e, em outros casos, a capacidade fica no limite ou muito próxima à massa desses implementos, não havendo, nesses casos, uma margem de segurança.

$\mathrm{Na}$ Figura 3, pode ser visualizada a relação da capacidade de levante pela vazão máxima da bomba nas diferentes Classes de potência motora.

A relação entre capacidade de levante e vazão máxima da bomba se eleva linearmente até a Classe III, diminuindo na Classe IV. Isso pode ser explicado pela maior vazão da bomba dos tratores da Classe IV em função da capacidade de levante, ou seja, o valor de vazão média aumentou 2,79 vezes na Classe IV quando comparado ao da Classe III. Já a capacidade de levante média foi apenas 1,6 vezes maior.

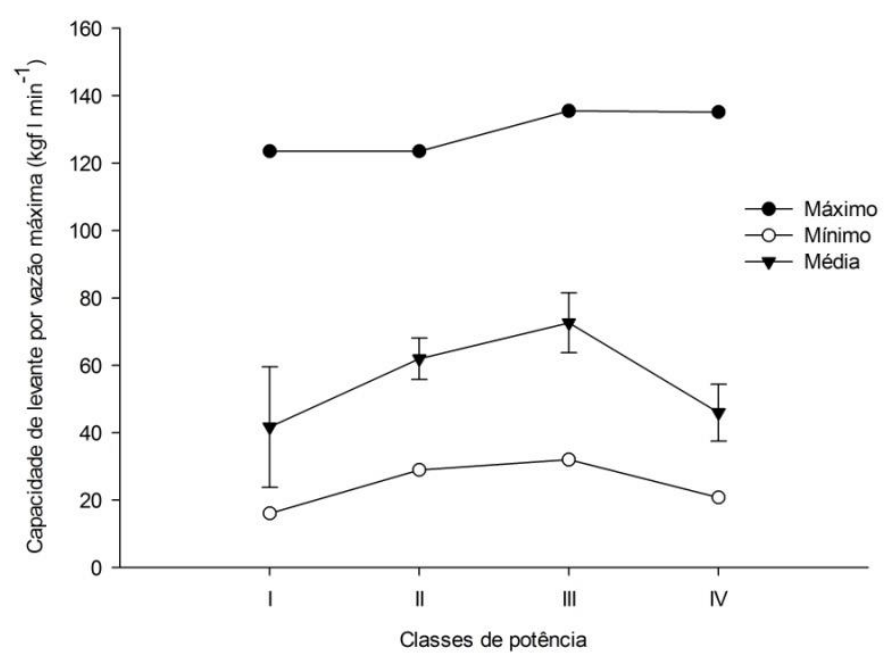

Figura 3. Relação da capacidade de levante do sistema hidráulico pela vazão máxima da bomba nas diferentes Classes

Essa associação também apresenta uma grande amplitude em uma mesma Classe, principalmente, nas Classes I e IV. Na Classe IV, alguns tratores possuem a mesma vazão máxima da bomba, comparando-se aos modelos de Classe III de mesma marca, o que explica elevada variação. Outro motivo é o grande intervalo de potência da Classe IV, que é classificado com tratores a partir de $147 \mathrm{~kW}$. No entanto, foram encontrados tratores de até $492 \mathrm{~kW}$ de potência motora. A menor vazão máxima da bomba da Classe IV foi de 51,8 $1 \mathrm{~min}^{-1}$, enquanto a maior foi de $4281 \mathrm{~min}^{-1}$. Já para os tratores da Classe I, essa alta variação se dá pela amplitude de capacidade de levante, sendo que o valor máximo de vazão da bomba é 2,5 vezes maior que o mínimo, enquanto que, na capacidade de levante, o valor máximo é 5,6 vezes maior que o mínimo. 
A relação da vazão máxima da bomba pela potência motora nas diferentes Classes de potência pode ser visualizada na Figura 4.

A variação média da vazão máxima da bomba relacionada à potência motora é diretamente proporcional, pois tanto a vazão quanto a potência se elevaram igualmente, com valores médios de 0,79 até 1,09. Na Classe I, essa relação é maior pela grande variabilidade da potência motora em comparação de uma vazão semelhante, como o caso de um trator de $10 \mathrm{~kW}$ de potência ter $231 \mathrm{~min}^{-1}$ de vazão, enquanto outros tratores têm potência entre 25 e $30 \mathrm{~kW}$ com vazão de $281 \mathrm{~min}^{-1}$, mostrando, nesse caso, a não equivalência. Já para as outras Classes, há uma relação proporcional.

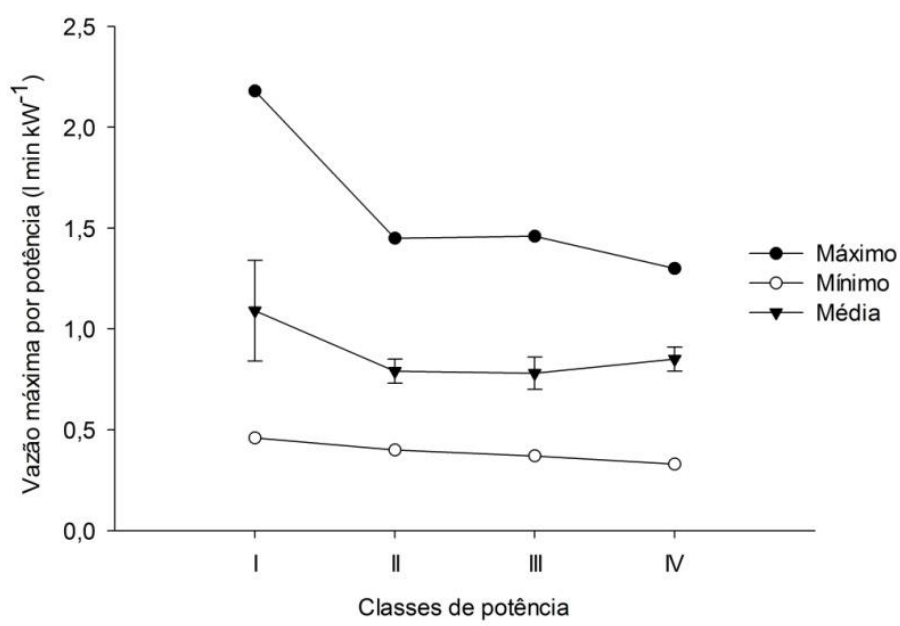

Figura 4. Relação da vazão máxima da bomba pela potência motora nas diferentes Classes

A Figura 5 ilustra a pressão máxima da bomba relacionada à potência motora nas diferentes Classes de potência.

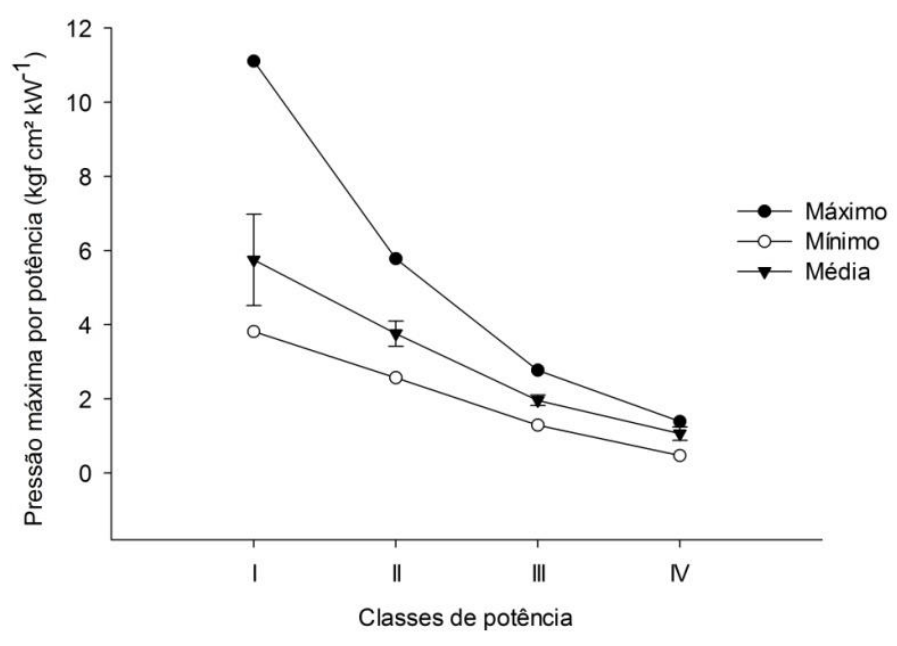

Figura 5. Relação entre pressão máxima da bomba pela potência motora nas diferentes Classes de potência

A relação da pressão máxima da bomba com a potência é inversamente proporcional, pois a pressão média se mantém sempre constante nas diferentes Classes de potência. Isso ocorre porque a relação da força aplicada sobre a área do cilindro hidráulico é proporcional, ou seja, ocorre um aumento de força no sistema juntamente com aumento do diâmetro do cilindro. Assim sendo, essa relação decresce porque a pressão é constante e a potência motora é crescente quando aumenta a Classe de potência. A maior variação na Classe I pode ser explicada pela grande variabilidade de pressão nessa Classe, com valores abaixo da média, chegando a valores mínimos de $120 \mathrm{kgf} \mathrm{cm}^{-2} \mathrm{e}$ máximos de $214 \mathrm{kgf} \mathrm{cm}^{-2}$, sendo que para as Classes II, III e IV, a pressão varia apenas de 180 a $220 \mathrm{~cm}^{-3}$, o que é atribuído a pressões das diferentes linhas de modelos, podendo ser da mesma marca em uma mesma Classe de potência.

\section{CONCLUSÕES}

A capacidade de levante hidráulico dos tratores apresenta incremento em função do acréscimo da massa total, da potência do motor e da vazão da bomba até equipamentos agrupados na Classe III. Máquinas dispostas na Classe IV apresentam pequena redução dessas relações em comparação às da Classe II e III pelo sistema de levante ser uma ferramenta secundária.

Tratores da Classe I apresentam a maior variabilidade da relação entre vazão máxima da bomba e potência motora quando comparados aos modelos das demais Classes.

A relação entre a pressão máxima da bomba e potência motora é decrescente, pois esta é relativamente constante nos diferentes modelos de tratores, enquanto que a potência se eleva quando se aumenta a Classe.

\section{SYSTEM CAPACITY HYDRAULIC LIFT OF TRACTORS TIRES IN BRAZIL}

\begin{abstract}
Tractor hydraulic system becomes important as a coupling mode for some farm implements, besides transmitting power. Therefore, this study aimed to verify the variations of engine power related to the lifting capacity of the three points, the maximum pressure and maximum flow of the pump, as well as to observe the lifting capacity in function the mass of tractors without ballast. For this, data were collected from 171 models from 11 different brands of tires farm tractors. They were classified by engine power according to ANFAVEA (Associação Nacional dos Fabricantes de Veículos Automotores) [1]. A
\end{abstract}


spreadsheet to collect the variables to be studied was built. The maximum pump flow was variable, in which less data were found, ranging from 39.13 to $62.16 \%$ in the different Classes. Tractors of class II and III had the best relationships when one of the variables was the lifting capacity. The average variation of the maximum pump flow related to motor power is proportional, i.e., both the flow as power rose equally with average values of 0.79 to 1.09 in different Classes. Lifting capacity has improved due to the increase of the total mass, of engine power and pump flow to equipments grouped in class III; from this, there was a small reduction in relationships because the lift system is a secondary tool.

Keywords: Three-point hydraulic system. Technical information. Selection of agricultural machinery. Hydraulic system pump.

\section{Referências}

[1] ANFAVEA; Anuário da Indústria Automobilística Brasileira de 2014. Disponível em: $<$ http://www.virapagina.com.br/anfavea2015/>. Acesso em 02/06/2015.

[2] VIAN, C. E. de F; ANDRADE JÚNIOR, A. M.. Evolução Histórica da Indústria de Máquinas Agrícolas no Mundo: Origens e tendências. In: CONGRESSO DA SOCIEDADE BRASILEIRA DE ECONOMIA ADMINISTRAÇÃO E SOCIOLOGIA RURAL, 48., 2010, Campo Grande. Anais... Campo Grande: Sociedade Brasileira de Economia, Administração e Sociologia, 2010.

[3] KUMAR, G.V. Development of a computer program for path generation of tractor hitch points. Biosystems Engineering, v.113, p.272-283, 2012.

[4] PRADE, R.; FRANCETTO, T. R.; DAGIOS, R. F.; RUSSINI, A. Avaliação da capacidade do sistema de levante hidráulico dos tratores agrícolas com tração dianteira auxiliar (TDA) de acordo com a sua classificação quanto à potência, Cuiabá, MT, 2011. In: Geração de tecnologias inovadoras e o desenvolvimento do cerrado brasileiro, 40.,2011, Cuiabá, MT. Anais... Cuiabá: Sociedade Brasileira de Engenharia Agrícola, 2011.

[5] REIS, Â. V. dos; SVERZUT, C. B.. Análise espectral das forças no sistema de engate de três pontos do trator agrícola. Revista Brasileira de Agrociência, Pelotas, v. 1, p. 19-22, 1995.

[6] VILAGRA, J. M. Adequação ergonômica de trator agrícola de média potência: construção e validação de um instrumento de avaliação a partir do construto de conforto, segurança e eficiência. 2009. 133f. Tese (Doutorado em Engenharia de Produção) - Programa de Pós-graduação em Engenharia de Produção. Universidade Federal de Santa Catarina.
[7] MIALHE, L. G. Máquinas Agrícolas: ensaios \& certificação. Piracicaba: FEALQ, 1996. 722 p.

[8] FRANCETTO, T. R.; DAGIOS, R. F.; FERREIRA, M. F. Informações disponibilizadas pelos fabricantes de tratores no Brasil para se proceder a uma comparação e seleção técnica do modelo a ser adquirido. In: CONGRESO LATINOAMERICANO Y DEL CARIBE DE INGENIERÍA AGRÍCOLA, 9., 2010. Vitória. Anais... Vitória: Sociedade Brasileira de Engenharia Agrícola, 2010.

[9] SILVA, M. R. da.; DANIEL, L. A.; PECHE FILHO, A.; Uso da teoria de números índices para adequação de semeadorasadubadoras de precisão. Revista Brasileira de Engenharia Agrícola e Ambiental, Campina Grande, v. 11, p. 222-229, 2007.

[10] BS ISO 730 British Standarts. 2009. Agricultural wheeled tractors - Rear-mounted three-point linkage - Categories $1 \mathrm{~N}, 1$, 2N, 2, 3N, 3, 4N and 4. Geneva: Standarts Policy and Strategy Committe, 2009. p.1-24

[11] GARAY, A. V. A.; BENÍTEZ, M. A. A.; HERNÁNDEZ, M. Á. S.; OSORNIO, R. C.; LÓPEZ, N. V.; SÁLLAGO, J. M. V.; HERNÁNDEZ, M. G.; SANTOS, M. M.; Impacto de las pruebas de tractores agrícolas em México: determinación de pontencia a la toma de fuerza, levante hidráulico, cabinas y marcos de seguridad. Revista Ciencias Técnicas Agropecuarias, Cuba, v.22, p.6-14, 2013.

[12] BIONDI P., MARAZITI F., MONARCA D. Technical trends of tractors and combines (1960-1989) based on Italian type-approval data. Journal of Agricultural Engineering Research, v.65, p.1-14, 1996. 